I Universidade de Coimbra, Faculdade de Economia, Coimbra, Portugal

elisio.estanque@gmail.com

Elísio Estanque ${ }^{\prime}$

\title{
A PRÁXIS DO TROTE: \\ BREVE ETNOGRAFIA HISTÓRICA DOS \\ RITUAIS ESTUDANTIS DE COIMBRA*
}

Este texto foi escrito originalmente em português de Portugal, onde a noção de trote tem a designação de praxe. A praxe é uma práxis que pode ser entendida em sentido amplo ou mais restrito. O Código que regula a praxe em Coimbra (com 290 artigos) ${ }^{\mathrm{I}}$ define-a simplesmente como "o conjunto de usos e costumes tradicionalmente existentes entre os estudantes". Numa linha que vai ao encontro da ideia de "ritual iniciático", do antropólogo Van Gennep (I98I), o historiador Paulo Archer de Carvalho, definiu as praxes como "a sobrevivência simbólica de rituais de passagem, de presentificação e de heterorreconhecimento, balizadas por gestos que tentam assinalar a desbestialização do aprendiz e a sacralização do ofício intelectual, partindo do princípio - consagrado na própria nomenclatura (o burro, a cabra, o chocalho, a "magna besta", etc.) - de que o ser humano é à nascença uma besta" (Assembleia da República, 2008). Tais rituais, por vezes considerados mecanismos de integração, visam "testar" ou "pôr à prova" o "novato", o "recruta", aquele que acaba de chegar a uma nova condição ou comunidade e que a ela deve submeter-se.

Ao contrário do caso brasileiro, essas práticas (trote/praxe) são, ainda hoje, um verdadeiro fenômeno de massas nas universidades portuguesas. Segundo estudo internacional recente, ${ }^{2}$ cerca de $73 \%$ dos jovens universitários portugueses afirmaram ter sofrido alguma praxe mais pesada quando entraram na universidade (enquanto a média dos países estudados era de $25 \%$ ), 
$59 \%$ dos estudantes portugueses afirmaram que tais atos tiveram "consequências psicológicas" em sua vida, e $20 \%$ revelaram que eles determinaram o abandono dos estudos.

Considerando o impacto sociológico junto à juventude estudantil portuguesa e ao mesmo tempo seu profundo enraizamento histórico, em especial na Universidade de Coimbra (de ora em diante designada por UC), o presente artigo procede a um levantamento (necessariamente sintético) das raízes históricas das tradições acadêmicas, recorrendo a registro etnográfico por meio do qual são revelados alguns dos contornos dos rituais iniciáticos e da riqueza patrimonial daquela que é conhecida como "cidade dos estudantes". Aspectos como a violência tradicionalmente associada a essas práticas; as tensões e a conflituosidade que, ao longo dos séculos, marcaram as relações entre a elite estudantil e a comunidade local; a possível conexão entre as praxes e os múltiplos movimentos socioculturais, musicais e políticos que caracterizaram sucessivas gerações; a questão da subalternização do papel da mulher e sua relação com a cultura "marialva" e sexista, numa universidade outrora exclusivamente masculina; e, por fim, as tendências mais recentes que o fenômeno da praxe vem adquirindo em Portugal - onde alguns casos e até tragédias, como a da Praia do Meco (I5/I2/2013), onde morreram afogados seis jovens estudantes na sequência de um ritual de praxe -, muitas vezes resvalando para o abuso e a violência, são algumas das dimensões que o presente texto procura explorar e discutir. A humilhação e submissão perante o poder que a maioria das praxes comporta parece exprimir uma tendência larvar na sociedade, em que o individualismo consumista se combina de forma perversa com lógicas de evasão e de entrega incondicional - e aparentemente voluntária - ao poder do mais forte.

\section{INVESTIDAS, CANELÕES, CAÇOADAS E TRUPES}

Fundada em I 290,3 a Universidade Portuguesa seria instalada pela primeira vez em Coimbra em I308. Um ano depois, o rei dom Dinis instituiu por decreto horas de estudo e recolhimento obrigatório para os estudantes, estabelecendo que os infratores fossem vigiados e sancionados pelos estudantes mais velhos (de acordo com sua própria hierarquia, com base exclusivamente na antiguidade de cada membro). Subjacente a esses regulamentos iniciais estava o estatuto exclusivista de que era depositária a estrita elite que, nessa primeira fase, se beneficiava do protetorado da monarquia. Foi então (I309) que dom Dinis, em sua Charta Magna Privilegiorum (versão atualizada da carta fundadora da universidade, de I290), estabeleceu um conjunto de medidas destinadas a disciplinar, mas também a proteger os estudantes. Nela se evidenciam algumas de suas preocupações quanto ao estatuto exclusivo da condição estudantil e definem-se medidas destinadas a acautelar a defesa de suas prerrogativas especiais. Pouco depois da transferência definitiva 
da universidade para Coimbra, em I537, foram estabelecidas disposições régias por dom João III, visando conter e proibir o ameaçador porte de armas, então de uso comum em situações de conflito em meio aos estudantes e entre eles e outros grupos populares.

Desde o início do século XVIII são identificadas as chamadas investidas, ou seja, atos violentos exercidos por grupos de estudantes mais velhos (em geral encapuçados), que incluíam troças e castigos infligidos aos novatos. Alguns desses atos relacionavam-se com os parcos meios de transporte da era medieval, quando as viagens a Coimbra eram extremamente morosas e não raro acidentadas. Os estudantes chegavam muitas vezes montados em burros, éguas e mulas. Cavalos e diligências seriam exclusivos dos poucos oriundos dos extratos mais elevados das famílias nobres e aristocráticas. Eduarda Cruzeiro (I979: 7I0) refere-se aos estudantes calouros que nesse contexto se tornaram "vítimas de arrieiros e estalajadeiros, exploradores vorazes que não lhes poupam as bolsas nem os corpos, usurpando-lhes os primeiros as montadas a meio caminho, ratilhando-lhes os segundos os confortos da cama e mesa que deviam proporcionar-lhes". Era esse o quadro com que se deparavam muitos dos novatos (calouros) pela primeira vez com seus colegas mais velhos.

É nas investidas que mais surge essa mistura de práticas entre a recepção ritualizada e humilhante do calouro e as ações arruaceiras, próximas da criminalidade. O célebre Rancho da Carqueja foi um dos grupos mais violentos dessa época (I720-I72I). Tantos distúrbios provocaram, incluindo o rapto de donzelas, 4 que o rei dom João V "mandou-os degredados para a Índia, e o seu chefe, o estudante canonista Francisco Jorge Aires, da Vila da Feira, acusado dum assassinato, foi degolado [no pelourinho, a 20 jun. I722], sendo a sua cabeça remetida para Coimbra, e aqui exposta na Praça de S. Bartolomeu (desde I de Julho de I722)" (Bastos, I920). A proibição de atos equivalentes foi decretada por dom João V em I727, conforme refere Ribeiro Sanches ${ }^{5} \mathrm{em}$ sua crítica aos costumes estudantis de então: "não havia defesa daquelas bárbaras e indecentes investidas, feitas com violência e desacatos, armados os agressores como para assaltar um castelo: e destes excessos resultaram mortes, incêndios e sacrilégios" (Cruzeiro, I979: 805).

A delinquência e o caos foram assumindo proporções particularmente graves ao longo da segunda metade do século XVIII, o que levou o governo do marquês de Pombal a promover, em I772, profunda reforma do funcionamento da universidade, não apenas nos processos e conteúdos de ensino ministrados, mas também no campo disciplinar, incluídos os critérios de admissão dos estudantes. O processo foi conduzido pelo reitor-reformador dom Francisco de Lemos (apud Cruzeiro, 1979: 8I7), que ainda assim se queixava, dois anos depois, de "alguma alteração da paz e ordem, causada por alguns vadios, que se vestiam de batina para passarem por estudantes, me- 
tendo-se pelas casas dos mesmos estudantes e perturbando-os". Em todo caso, na sequência da reforma, o número de estudantes da UC foi substancialmente reduzido, passando em poucos anos de cerca "de 3.000 para apenas 800 nos primeiros tempos depois dela" (Cruzeiro, I979: 8I7; ver também Torgal \& Dias, 2015).

As investidas consistiam em perseguição, sujeição e violência física aplicadas aos novatos, as quais se podem assemelhar aos "julgamentos" e atividades das "trupes" (que continuam a existir, no âmbito da atual praxe), incluindo humilhação pública, uso de palmatórias até provocar sangramento e corte de cabelo rente. Podiam, portanto, reunir um pouco de tudo o que constituísse práticas abusivas tais como insultos, troça, tourada, caçoada ou a patente. Caçoada e troça seriam - quando isolados - atos em que a violência física estaria bastante atenuada (ao contrário das investidas), sendo aqui a variante simbólica que mais sobressaía. O canelão ${ }^{6}$ era igualmente ato de grande dureza aplicado aos calouros, entendido como forma de pagamento de direitos à entrada material e simbólica da UC, no caso, a Porta Férrea. Quando, em I864, foi inaugurada a linha de estrada de ferro que liga Lisboa, Coimbra e Porto, o largo da Portagem era local de eleição para confrontar os novatos com as primeiras investidas, troças e rituais, principalmente no mês de outubro, mas que se repetiam ao longo do ano escolar. O cenário incluía todo um cardápio de iniciativas e terminologia muito própria. Pelo menos até meados do século XX, o mundo das tradições acadêmicas de Coimbra tinha criado e reproduzido uma cosmologia e um estilo de vida próprios, que só teve o alcance que teve porque foi criação de uma elite restrita e poderosa (Nunes, 2004).

O Foro Acadêmico (ou Juízo da Conservatória da UC, criado por dom João I em I408) garantia aos membros do corpo universitário status de exceção, permanecendo resguardados das exigências da justiça civil (dele fazia parte a prisão acadêmica, instalada em I593 e extinta em I834).7 A ele se liga a generalização do uso do traje acadêmico, ${ }^{8}$ destinado a distinguir o corpo universitário da restante sociedade civil. As prerrogativas derivadas do vínculo à UC atingiram tal importância, que alguns procuraram tirar proveito disso. Ao longo dos séculos XVII e XVIII foi possível a certas categorias de funcionários inscrever-se como estudantes, ainda que algumas vezes só o fossem de nome. Após a extinção, em I834, do Foro Acadêmico, foi criada em I836 a Polícia Acadêmica, na sequência de pressões corporativas que exigiam a preservação da autonomia universitária, a que dona Maria II acedeu. Fontes consultadas referem que em I854, o patrulhamento da cidade era organizado em três rondas, tendo os arqueiros ordem para obrigar os estudantes a recolher-se após o toque vespertino do Cabra (um dos sinos da torre da universidade, ver nota I2). Cada turno era assegurado por seis soldados e um a dois arqueiros (Gama, I964, apud Lamy, I990). A conduta dessa polícia junto à comunidade estudantil 
e à população de Coimbra seria, contudo, objeto de controvérsia e contestação, culminando, já no período da I República, com sua extinção.

De acordo com a mesma fonte, a partir de I883, ocorreu redução de competências e privilégios da Polícia Acadêmica, devido à pressão de sentido inverso que a sociedade vinha exercendo contra a situação vigente, visto que

existia uma cada vez menor tolerância aos desacatos estudantis, pois que ainda muitos dos mesmos eram resolvidos internamente (à luz do regulamento disciplinar da Universidade), considerando-se, por exemplo, que muitas infrações mereciam penas mais duras do que o encarceramento na prisão acadêmica (que, na verdade, nessa altura, era algo já pouco duro - os presos recebiam visitas, víveres, e até estudantinas vinham tocar à janela dos presos - e era antes visto como um feito heroico (blogue Notas \& Melodias). ${ }^{9}$

As primeiras referências às trupes remontam a meados do século XIX e supõe-se que seu surgimento esteja associado não diretamente ao fim do Foro Acadêmico, mas à redução de funções e competências atribuídas à Polícia Acadêmica, desde r883. Trupes são grupos de estudantes (pelo menos três) subordinados a um chefe, formalmente destinadas a zelar pela observância da praxe, executar um "julgamento" (de calouro) ou cumprir uma diretiva do Conselho de Veteranos. ${ }^{\text {Io }}$ Ainda hoje se mantêm, muito embora quase sempre envoltas em controvérsias e contestações por parte de amplos setores sociais e estudantis (agem usando traje acadêmico e sem outras cores visíveis que não o negro). O chefe da trupe é o estudante mais velho do grupo (pelo menos "pastrano" na hierarquia, ${ }^{\mathrm{II}}$ ) que sempre se faz acompanhar dos três símbolos elementares da praxe: a tesoura, a colher e a moca. Em épocas passadas, as trupes eram o principal fator de controle e de exercício de violência sobre os novatos. Surpreendido fora de casa após o toque vespertino do Cabra (entre seis e seis e meia da tarde), o calouro "tresmalhado" (na rua em hora indevida) ${ }^{\mathrm{I2}}$ podia ser caçado por esses grupos de estudantes mais velhos, armados de mocas, tesourões, palmatórias, pistolas, e ser vítima de tonsura parcial ou completa e de golpes de palmatórias (antigamente chamados de bôlas) nas mãos ou nas unhas. Era-lhe dada, no entanto, a possibilidade de defender-se em duelo com o chefe da trupe e, caso vencesse, não sofreria as sanções (Frias, 2003).

Há relatos curiosos e ilustrativos de como essas ações constituíam uma mistura, às vezes perigosa, de ironia corrosiva, pressão psicológica e humilhante exercida sobre os novatos e, em geral, violência física, que não poucas vezes assumia formas macabras e criminosas. De acordo com Sousa Lamy (I990: 694), "na noite de 26/I2/I84I, uma patrulha do corpo de segurança fuzilou pelas costas José Costas Lobos, terrível facínora estudante do $3^{\circ}$ ano [pelas costas por estar em fuga]" e "em I858, vários 'troupistas' foram hóspedes da prisão acadêmica durante oito dias, entre os quais os bem conhecidos Antero de Quental e Alberto Sampaio". 
O termo praxe começara a ser usado a partir da segunda metade do século XIX; concretamente, algumas fontes citam 1863 como o ano da primeira referência conhecida a esse ritual, então identificado como selvagem, invocando a natureza cruel e violenta já então atribuída a esses atos (Nunes, I989).

Referências escritas aos rituais estudantis para trás de I850 são rarefeitas, tendo em conta os processos dominantes de transmissão oral, passados aos mais novos através dos veteranos, de antigos estudantes para filhos e de futricas para calouros, num processo onde intervinham barbeiros, alfaiates, taberneiros, engomadeiras, criadas domésticas, funcionários da UC e proprietárias de bordéis (Cruzeiro, 1979).

Em todo caso, a principal referência dos rituais e tradições estudantis foi, desde meados do século XVIII, o clássico Palito Métrico. ${ }^{\text {I3 }}$

Em Coimbra é muito clara a persistente contradição que definiu ao longo dos tempos a relação entre os estudantes e a restante população da cidade (os chamados futricas ${ }^{\mathrm{I} 4}$ ). A partir de meados do século XIX, num período em que o associativismo acadêmico (e também nos meios artesãos e operários oitocentistas) começava a ganhar força, surgiram na cidade diversas instituições, tais como a Academia Dramática de Coimbra (I852), o Clube Acadêmico (I86I) e, da fusão de ambos, a Associação Acadêmica de Coimbra (I887). Anteriormente fora também criada a Sociedade de Instrução dos Operários (I85I); mas em contraponto com diversas iniciativas beneméritas dos estudantes chegou a formar-se a Liga Acadêmica, visando "sustentar o afastamento de todas as relações dos estudantes com os filhotes da terra, fazer a ronda noturna pela cidade para a proteção dos estudantes e organizar uma cooperativa de consumo em que por conta dos associados mandassem vir de fora de Coimbra os gêneros alimentícios" (Cruzeiro, I979: 83I). Ainda em finais do século XIX permanecia uma taxonomia muito particular do universo estudantil, como se percebe na sentença de condenação de um estudante, relatada por Teófilo Braga (I902): "Mostra-se outrossim que, entrando em casa de uns novatos, cinco homens, quatro mascarados, era o quinto réu sem máscara, e buscando positivamente a um novato [...] o mandaram despir nu, e lhe deram muitos açoites com umas disciplinas, de que correra sangue, e muita palmatoada, e lhe cortaram o cabelo rente pelo casco [...]".

\section{PRAXE, HUMOR E BOÊMIA ESTUDANTIL NO INÍCIO DO SÉCULO XX}

No início do século XX, antes e depois da queda da monarquia, viveram-se em Coimbra tempos de controvérsia em torno da praxe. Diante, porém, de clima político tão intenso como foi o da sequência da implantação da I República (5/IO/I9Io), o fenômeno esbateu-se, embora se mantivesse tema polêmico. Ainda na fase anterior, em I902, já surgiam visões que denunciavam alguma decadência desse ritual: 
a praxe acadêmica é uma sobrevivência de costumes de gerações que a História já de há muito arrecadou, numa vala comum, fria e insugestiva. É uma tradição em guerra aberta com o progresso, uma espécie de hereditariedade doentia e revela-se numa triste promiscuidade de sintonias. Em 1905, contra o que era costume, José de Arruela e outros companheiros, procuram receber com simpatia e afabilidade os novos estudantes; em igro, em nome da liberdade, a praxe é praticamente abolida, para ressuscitar em I9I9 (Prata, 2002: 256).

O importante livro de Trindade Coelho, In Illo Tempore (I902), retrata bem o ambiente dessa época, em que transparece a cultura meio marialva, meio satírica e irreverente, que se traduz no incentivo ao "despique" e ao contraditório mediante provocação, ironia e sarcasmo (o latim macarrônico tornou-se de uso frequente na linguagem praxista). Isso num tempo em que a violência sobre os novatos tinha como principal função suscitar a réplica e a resposta imaginativa. Já vimos que o ambiente burlesco e desbragado tanto nos remete às atmosferas lúdicas e de boêmia juvenil quanto evidencia o papel do sarcasmo e do riso. As figuras mais populares no meio estudantil eram, sem dúvida, aquelas que melhor personificavam a dimensão humorística. Uma delas foi o Pad'Zé que, além de chefe de trupe, foi estudante irreverente. A esse propósito vale a pena lembrar que, já nessa época, as repúblicas estudantis ocupavam lugar de destaque. Como refere Manuel Alberto Prata (2002: 253), "as repúblicas constituem não só espaços de sociabilidade geradores de muita camaradagem, mas também um tempo de enriquecimento cultural, de diversão e de lazer. Era Afonso Lopes Vieira quem, na mansarda do Pad'Zé, propunha que 'se lesse a Bíblia e Camões, se representasse Hamlet, se escrevesse e se discutisse adorando a Arte e se rendesse também culto à vida em festins noturnos'".

Veja-se o caso de um personagem que passou por Coimbra no início do século XX, conhecido pela alcunha de Pássaro. Segundo o relato de Trindade Coelho (I902), fez-se "legislador" da primeira Festa das Latas, que decorreu de forma organizada em Coimbra, em 1903, no texto (escrito durante uma aula do quarto ano) Aux Lates Citoyens, que bem espelha a irreverência estudantil em tempos de viragem sociopolítica. Esse personagem assim se autodefine em seu característico humor: ${ }^{\text {I5 }}$

Eu, Dom Chinfrim Banzé, por graça da rapaziada amiga, e de Sua Majestade Imperial a Arruaça, Inspetor da Troça, Chanceler-Mor do Pagode, Cavaleiro Professo da Nobilíssima Ordem da Bolsa Vazia, Grã Cruz da Piada Fina e do vinho do Pancada, socio de mérito e effectivo de varias associações de Prego e de Pendura, tanto nacionais como estrangeiras, condecorado com a medalha de ouro das campanhas do Canelão e do Corte-de-Cabello, admirador lamecha encartado do sopeirame da Alta e Director syndico em chefe da pantagruelica festividade das Latas, etc., etc. (Trindade Coelho, I902: I5-16).

Desde inícios do século XX e sobretudo no período da I República (I9IoI926) - paralelamente aos excessos de ritualismo e de violência - expandiram- 
se de modo bem rápido a politização dos estudantes e, com ela, as ações de protesto, sobretudo a reivindicação de direitos e condições para o pleno exercício das liberdades cívicas. Tal tendência não poderia deixar de contaminar os estudantes, em especial nesse período particularmente agitado da sociedade portuguesa. A chamada Tomada da Bastilha (que ocorreu na noite de 24 para 25 de novembro de I920) foi um dos momentos culminantes dessa atmosfera, quando um grupo de estudantes invadiu e ocupou o Clube dos Lentes (um salão luxuoso para lazer dos professores), numa ação verdadeiramente "revolucionária", exigindo espaço condigno para sede da Associação Acadêmica de Coimbra (AAC), até então inexistente.

As atmosferas do quotidiano da cidade, entretanto, embora sem dúvida sujeitas à evolução dos tempos, permaneceram durante séculos num quadro em que, apesar da presença estudantil, era bem visível a pobreza e a degradação das estruturas, das habitações dos estudantes e da paisagem urbana em geral. Sabemos por um lado que as origens sociais do corpo estudantil eram predominantemente das classes superiores - os fidalgos, a nobreza de toga, filhos de morgados, de "brasileiros", ${ }^{16}$ de ricos comerciantes e lavradores das redondezas -, mas, como refere Eduarda Cruzeiro (I979: 8I2), esse corpo se formava "também por alguns menos afortunados e mesmo pobres". Depreende-se desses relatos que os estudantes, tivessem poucos recursos ou fossem gastadores compulsivos, uma vez esgotados os meios de subsistência começavam, uns e outros, a socorrer-se "de expedientes, explorando, na medida do possível, os seus companheiros e todos os que a isso se prestassem".

Tais ambientes, ainda que em muitos casos denunciando alguma falta de dinheiro, não impediam, por outro lado, certa vida faustosa ou pelo menos de excessos, muitos dando-se ares de poder econômico que não possuíam. Ter muito dinheiro e "gastá-lo depressa" pareciam constituir regra em determinados meios. Isso ilustra também o simbolismo dos ambientes informais de lazer, em que a afirmação de status exige postura ostentatória, como reverso da angariação de simpatias e popularidade. Pagar sorvete, chocolate ou copo de vinho para todos era ato que sempre caía bem entre os convivas de ocasião. Esses modos de vida mundanos e algo desregrados foram, desde sempre, viveiros de excesso. São, portanto, espaços de sociabilidade inseridos em zonas, digamos, "laterais" às instituições - ou, se preferirmos, situados na fronteira entre a "normalidade" social e a "marginalidade", às vezes, nesta mergulhando -, em que, conforme diversos registros históricos testemunham, tendem a florescer movimentos e formas de pensamento alternativos e dissidentes.

Pode dizer-se que foi nesses meios, ou em outros semelhantes que começaram a grassar na Europa oitocentista, que cresceram os primeiros movimentos de intelectuais "boêmios". ${ }^{17}$ Embora com características bem distintas, 
e no contexto de um país ainda marcadamente rural e pobre, Coimbra favoreceu - ainda que em simulacro - o surgimento de ambientes idênticos, pelo menos em meio à elite dos estudantes universitários. Os segmentos estudantis de status mais elevado poderiam exibir de modo particular sua condição privilegiada: "excesso de serviçais, um e às vezes três criados; se é cavaleiro tem seu cozinheiro, um criado e um pajem ou, pelo menos um negro" (Cruzeiro, I979: 8I3). Quando, porém, o dinheiro começava a escassear, a imaginação e o engenho procuravam suprir as necessidades, incluindo o recurso ao conhecido "prego" (as antigas casas de "penhores"). Também o jogo e a prática das rifas, envolvendo os mais diversos objetos pessoais (valiosos ou não, como relógios, anéis, livros, pistolas, esporas, peças de vestuário etc.), deram azo a um hábito de transações e sorteios de que o já citado Palito Métrico se fez eco.

Era grande a variedade de personagens marcantes no meio estudantil. Em épocas diversas, mas sobretudo desde finais do século XIX e ao longo da primeira metade do XX, foram-se perfilando nas atmosferas da informalidade nomes como os já mencionados Pad'Zé e Pássaro; outros, como Fonseca, Condorcet, Pantaleão, Castelão de Almeida, reforçam a ideia de que a irreverência e a boêmia estudantil, ${ }^{18}$ ainda que contribuíssem para aumentar o número de anos de permanência na universidade, tornaram-se importantes fatores de enriquecimento formativo. À semelhança dos novos costumes urbanos influenciados pelos movimentos culturais que se seguiram à Revolução Francesa, movimentos transgressivos e boêmios atravessaram a Europa e foram-se afirmando como parte de um patrimônio enriquecedor da academia e das contraculturas estudantis, dando origem à germinação de movimentos socioculturais de grande impacto, dos quais, aliás, nesse período, Coimbra foi palco.

Com tantos séculos de história, a UC foi, tal como outras universidades europeias, instituição fundamental na formação das elites políticas, culturais e intelectuais do país. Para além dos conhecimentos e da importância formal dos títulos acadêmicos, a frequência à universidade era, por si só, garantia de prerrogativas distintivas e de elevado status. O peso da história, a estreita imbricação da universidade na cidade, e sua projeção como cidade universitária contribuíram para construir uma identidade particular, fortemente devedora da presença estudantil e do saber acadêmico. Esses atributos históricos fizeram da Lusa Atenas uma das cidades mais glorificadas e cantadas por poetas e escritores de todas as épocas. Camões, Garrett, Antero, Eça ou, mais recentemente, Manuel Alegre, são apenas alguns dos nomes célebres que nela deixaram suas marcas. E, além da literatura e da poesia, também o fado e a guitarra de Coimbra. ${ }^{19}$ Não sendo essa a dimensão principal do presente texto, é importante, contudo, realçar seu papel na estruturação da cultura estudantil em geral e, em particular, no contributo que teve na consolidação da "contracultura" de resistência, especialmente nos últimos anos do Estado Novo. 


\section{A MASCULINIDADE E A EMERGÊNCIA DA QUESTÃO DA MULHER}

Aspecto incontornável para uma reflexão sobre as tradições acadêmicas e a violência simbólica prende-se à marca masculina que, desde sua gênese, acompanhou o sistema de ensino superior. Em Portugal a primeira mulher a frequentar universidade foi Domitila de Carvalho. ${ }^{20}$ Ingressou na UC em I89I, tendo cursado e concluído os cursos de matemática, filosofia e medicina nessa mesma década, e concluído o doutoramento em I904.

Evidentemente a questão da desigualdade de status entre homem e mulher é mais sentida nos ambientes em que o convívio entre ambos os sexos é cerceado, por uma razão ou por outra. Quartéis, colégios internos, seminários, por exemplo, constituem coletividades em que, em geral, a segregação sexista ganha expressão nos códigos internos. Apesar de a tradição universitária constituir o principal foco da presente reflexão, importa recordar que tais práticas não são historicamente exclusivas da universidade. Os antigos "colégios internos" e outras instituições disciplinares e fechadas, como casas de correção dedicadas à educação ou reinserção de jovens celibatários - sobretudo as instituições masculinas - promoveram e recriaram suas normas de conduta submetendo os mais novos e recém-chegados à autoridade dos mais velhos. Em resumo, a violência simbólica e física foi, ao longo de muito tempo e sob diversas formas, como o uso da régua, da colher de pau ou do ponteiro, considerada ingrediente necessário à educação. Em particular em regimes autoritários, o papel da instituição escolar não foi alheio à violência e até a legitimou como condição para promover a civilidade, a disciplina e o respeito pelos valores e costumes protegidos pela autoridade (Foucault, I977; Elias, I989).

Nas tertúlias em cafés, tabernas e bordéis permitia-se todo tipo de misturas, incluindo diversas formas de expressão artística e musical, as baladas e o dedilhar de uma guitarra animando os ambientes de excesso, consumo de álcool, intercâmbio sexual etc. Embora sendo espaços interclassistas, de diversidade e de encontro, eram, contudo, restritos apenas a uma parte da elite - a que rejeitava mais abertamente os costumes convencionais e burgueses -, aquela que pretendia subverter as regras e marcar a diferença ao desprezar esses ambientes de salão, próprios da alta sociedade. Tais atmosferas, é bom enfatizar, eram carregadas de masculinidade, tal como a população estudantil da universidade formou um mundo exclusivamente masculino até as primeiras décadas do século passado. De resto, as próprias atividades lúdicas invocavam recorrentemente esse fato, visível por exemplo nas letras das baladas, nas serenatas e em outros rituais da vida estudantil, em que sobressaía a presença dominante de um éthos marcado pela virilidade e pelo sexismo.

Vigorava no país, não devemos esquecer, uma mentalidade que, além de centrada nos valores tradicionalistas, cultivava referências conservadoras 
e formas de subalternização da mulher. Embora a pretexto de um discurso romântico, a condição feminina continuava a ocupar papel secundário - às vezes de mero objeto sexual -, mesmo no âmbito da cultura estudantil (cujo estereótipo mais vulgar era a figura da "sopeira"), pelo menos até a primeira metade do século XX. Como sabemos, o regime salazarista procurou perpetuar essa moral conservadora e machista, em larga medida apoiada na doutrina da Igreja católica. ${ }^{21}$ No entanto, a universidade foi-se feminizando e nos anos I950 já acolhia presença significativa de mulheres. Apesar do regime autoritário e dos poderosos obstáculos culturais, portanto, a fagulha da libertação sexual da década de I960 alcançou Portugal, seu universo estudantil incluído. Nessa época ganhou expressão o debate sobre as condições de "convívio" entre os dois sexos e entre academias diferentes, quando a discussão em torno dos "papéis sexuais" já vinha há algum tempo sendo levantada em Coimbra.

Momento alto desse primeiro debate em torno da temática da libertação da mulher foi a publicação da "Carta a uma jovem portuguesa". Assinada por um anônimo A., seria posteriormente reivindicada por Artur Marinha de Campos.

Jovem portuguesa! Dou-te a minha mão e o meu corpo. Sinto os teus dedos, o teu braço. Sinto um corpo jovem junto ao meu. Mas não sou um molde; sou um jovem diferente de ti. Um rapaz para quem o amor é a concretização sexual, única diferença nas relações entre o homem e a mulher, que devem decorrer no mesmo plano que nas relações de homem para homem. Nós temos a mesma liberdade. Foi um impulso semelhante de dois seres livres o que nos uniu (Anônimo, I96I).

O autor interpela a figura abstrata de uma "jovem portuguesa”, exaltando em tom poético sua perturbação perante a situação social da juventude feminina, marcada por um "determinismo" conservador que a obrigava a viver do "lado de lá desse muro: o mundo inquietante da sombra e da repressão mental", mencionando, que oprime e subjuga "a concretização sexual do amor". Os efeitos da carta ultrapassaram o circunscrito perímetro da academia, provocando uma onda de indignação por parte das camadas mais alinhadas com o regime, que viam no texto "um ataque frontal à religião cristã e à Moral que está nos fundamentos da nossa sociedade” (Cardina, 2008a: I30).

\section{POLITIZAÇÃO DA TRADIÇÃO: ANOS 1960}

As causas diretas do movimento estudantil, além de algum contágio dos ventos de rebelião juvenil internacional que, apesar de tudo, terá penetrado o país, prendiam-se sobretudo à asfixia em que se vivia em termos políticos. Uma universidade muito conservadora, ausência de liberdades políticas, cívicas e associativas, um Estado centralista e fortemente repressivo, e sobretudo uma guerra colonial para onde eram mobilizados à força sucessivos contingentes de jovens (muito deles mortos ou feridos em combate em An- 
gola, Guiné-Bissau e Moçambique). É nesse contexto que, no início da década de I960, e na sequência de um trabalho cultural exercido na clandestinidade a partir das repúblicas (residências de estudantes com estatuto especial na sua ligação à UC), foi eleita uma lista de esquerda para a direção-geral da AAC, apoiada pelo Conselho de Repúblicas (a estrutura federativa do conjunto das referidas casas comunitárias). Recorde-se que o ambiente comunitarista que se vivia nas repúblicas ocupou, a esse respeito, lugar de relevo, ao estimular irreverência, solidariedade e espírito crítico entre os estudantes. Foi nessa medida que se afirmaram como focos decisivos de diversos movimentos e formas de dissidência em face dos padrões convencionais e do próprio regime de Salazar-Caetano (Estanque, 2010). O ambiente das repúblicas, no entanto, também evoluiu significativamente desde meados do século XX. Enquanto no início desse ciclo, na carta constitutiva do Conselho de Repúblicas (de I948), se declarava que elas estavam "unidas pela praxe", tal posição foi evoluindo para uma concepção mais culturalista e interventiva com a entrada na década de I960. "Em lugar de se focalizarem na sua vertente mais boêmia e jocosa, as Repúblicas passam a autodefinir-se como 'centros de formação cultural do estudante, agrupamentos regidos pelo princípio democrático da autogestão, gozando de independência econômica e ideológica, libertas de qualquer gênero de tutela'" (Cardina, 2008b: I25; ver também Cruzeiro, I989; Namorado, I989 e Estanque, 2016).

Apesar do fechamento do país, os ecos dos movimentos sociais internacionais e da mudança de mentalidades suscitada pelo Maio de 68 e durante os sixties não deixaram de contagiar alguns setores da juventude estudantil. Desde os finais da década de I950 as correntes oposicionistas de esquerda já vinham apostando numa concepção solidarista da praxe, procurando influenciar os meios tradicionalistas no sentido de lhes incutir um novo conceito de "política", ao mesmo tempo que se visava imprimir ao movimento associativo uma orientação reivindicativa e combativa, que se traduzia, na linguagem da época, em uma perspectiva "sindicalista" do movimento estudantil (Estanque \& Bebiano, 2007; Cardina, 2008b). Essas diferentes dimensões da cultura estudantil eram então praticamente indestrinçáveis: "O pôr em causa da Universidade salazarista e dos fundamentos em que esta assentava [...] fez-se incorporando nessa cultura [acadêmica] em movimento, feita ação política, os valores e as tradições da memória coletiva da juventude universitária, especialmente Coimbra. Por outro lado, a política foi - pela fraternidade, no apelo inteligente e afetivo, na música, na palavra, no canto, na imaginação, no amor, na transgressão e na festa - em si mesma, uma nova expressão cultural" (Martins, I982 apud Frias, 2009).

Essa estreita ligação entre tradição acadêmica, associativismo estudantil e ação política podia exprimir-se, por exemplo, na inclusão de imagens ou mensagens de denúncia do regime nos rituais. Isso ocorreu, aliás, no des- 
file da Latada de I96I/I962, em que um carro puxado por um estudante negro ostentava a frase do regime "Angola é nossa!" ou ainda um cartaz bem sarcástico que exibida a frase: "O Tó [Salazar] tem um cancro. Coitado do cancro!". Em algumas fases desse período, "a praxe acadêmica desempenhou papel importante como instrumento político na oposição à ditadura de Salazar e à guerra colonial, uma vez que foi usada para disfarçar de tradições acadêmicas as intervenções antirregime" (Dias \& Sá, 2013: 22). Note-se, porém, que em Coimbra a contestação ao conflito nas colônias ocorreu apenas a partir de final da década de I960. Foi ainda por volta desse período (I96I-I964) que se expandiram na cidade as novas sonoridades musicais e produção poética que viriam a ser conotadas com a nova canção de protesto. Novas referências e novos valores culturais eram transmitidos pela música, as baladas líricas e a poesia. Aí se destacaram nomes como José Afonso e Adriano Correia de Oliveira e, com eles, inaugurou-se o irreverente movimento musical-cultural de contestação ao regime. ${ }^{22}$

Pode-se, portanto, dizer que a conjugação de movimento estudantil e tradições ajudou a camuflar a resistência organizada na clandestinidade. Miguel Cardina refere-se a isso quando afirma: "a utilização dos rituais e da simbologia praxista permitia que a contestação se inserisse no fluxo das vivências tradicionais coimbrãs, o que não só lhes conferia legitimidade como despertava uma certa complacência por parte da elite dirigente nacional, para quem Coimbra era ainda, simultaneamente, o lugar de um certo espírito corporativo, boêmio e romântico e uma instituição universitária produtora dos cérebros do regime" (Cardina, 2008b: II7). Além disso, Salazar saiu do cargo em 1968, sucedendo-lhe Marcelo Caetano (ex-reitor do Instituto Superior Técnico de Lisboa) com a promessa de uma abertura do regime. Daí a aura de um período que ficou na história como a "Primavera Marcelista" (leia-se bonita, mas de curta duração).

Os acontecimentos da chamada crise acadêmica de I969 desencadearam um período de luto acadêmico, ${ }^{23}$ que se traduziu na interrupção das festas estudantis e da praxe aos calouros. Desde então e até finais da década de I970, o uso do traje só foi admitido em momentos especiais, ${ }^{24}$ ou seja, como forma de protesto contra o regime. Já nesse tempo, todavia, o uso do traje passou a ser visto como algo pouco compatível com a ação contestatória dessa geração estudantil. Foi nesse contexto que se decidiu interromper as festas e os cortejos habituais, assim como a praxe, mas estabeleceu-se também o preceito de usar a capa descaída pelos ombros, com o colchete da batina apertado no pescoço e com fitas, pins e insígnias escondidos. Por outro lado, ao contrário da ideia que hoje prevalece entre os estudantes, os momentos de controvérsia, relacionados com a tradição e seu significado político, antes e depois de I969, continuaram a ocorrer em meio a múltiplas reconfigurações e formas de ação coletiva, quer no terreno sociopolítico quer 
na dimensão mais estritamente cultural e ritualista, em que a praxe permaneceu como foco de polêmicas - se bem que mais esporádicas - que alimentavam a dissensão entre grupos rivais (Cardina, 2008b).

É costume pensar-se que os períodos mais intensos de mobilização cívica - quando a Gesellschaft (sociedade) se reforça, e a Gemeinschaft (comunidade) recua - estimulam a mudança, mas podem também contribuir para maior coesão social. Embora num registro diferente, muitos cientistas sociais citam Émile Durkheim, que no século XIX mostrou como a perda dos laços sociais e o esbatimento das crenças comuns conduzem a patologias, em especial quando os indivíduos se submetem sem limites à força coerciva do social, abdicando de seu envolvimento ativo na revitalização das crenças e dos valores morais da sociedade.

\section{EM NOME DA TRADIÇÃO, A PERVERSIDADE DO PODER}

O elemento psicológico é, sem dúvida, o epicentro de toda esta lógica perversa: criam-se expectativas que, em geral, exorbitam a vulnerabilidade da vítima, deixando-a na incerteza do que lhe pode acontecer, mas ao mesmo tempo como que procurando medir até onde vai sua capacidade de aguentar. É nesse jogo que se procura testar a força mental do outro. É aí que o poder simbólico se insinua, entre a capacidade de "engolir" as situações mais repugnantes e o livre-arbítrio de quem está investido de poder e que muitas vezes transmite a mensagem: "não vou fazer mal a você, mas, se eu quisesse, poderia fazer". O jogo pode, portanto, evoluir em sentido inverso, isto é, da situação de "abuso" para o gesto de afeto e solidariedade. Muitos dos estudantes que entrevistei mencionaram exatamente isso. Quando se sai do contexto de praxe para o ambiente de "festa" as relações se alteram substancialmente. É importante realçar que o calouro pode também conquistar alguma ascendência sobre os "doutores". Um dos momentos em que isso se torna mais evidente é na disputa por "afilhados/afilhadas" por parte de "padrinhos/ madrinhas", uma vez que, entre os mais velhos, torna-se símbolo de status o fato de conseguir um grande número de afilhados. De qualqeur forma, um dos pontos que deve ser realçado e compreendido no que respeita às atitudes e à obediência do calouro refere-se a sua dificuldade de dizer "não!".

Vale a pena registrar uma situação de observação direta ocorrida em finais de 20I4 no Jardim Botânico, um parque verdejante de Coimbra, mas relativamente sossegado, sobretudo no inverno, como era o caso, e de clima algo agreste. Ao testemunhar os comportamentos daquele grupo em êxtase coletivo, a leitura da situação só poderia tornar-se ainda mais crítica, uma vez que se trata de práticas disciplinares - envoltas em forte poder simbólico-, mas ao mesmo tempo reveladoras de consentimento e naturalização da submissão. Vejamos então o relato que elaborei a respeito: 
Por casualidade, quando passava há uns dias no Jardim Botânico, em Coimbra, num dia chuvoso, notei ruidosa festa em redor do lago artificial. Aproximei-me, olhei, vi e fotografei: cerca de uma centena de jovens, a maioria em traje acadêmico, celebrando uma atividade da praxe, rodeava o lago, onde uns quantos calouros (eles de um lado, elas do outro) tomavam banho, encolhidos debaixo d'água e agarrados ao beiral, sob chuva abundante, alguns tremendo de frio, enquanto os 'doutores', de colher de pau em riste, lhes despejavam colheradas de água na cabeça. Alguns já tinham saído, ainda a tiritar e embrulhados em capas, mas quando os interpelei asseguraram-me que estavam ali de espontânea vontade... Uns dirão que isso não é a 'verdadeira' praxe, outros, como esses, garantem que tudo acontece livre e voluntariamente. Não é preciso ser sociólogo para saber que a 'vivência' não é requisito decisivo para um conhecimento rigoroso, às vezes até pelo contrário (Estanque, 20I4).

É verdade que os calouros saíam do lago tremendo de frio e agarrados às capas de seus "padrinhos". E todos eles confirmaram que tudo o que ali se passara tinha sido de livre vontade e em nome da integração que a praxe proporciona. Afirmações que, no entanto, foram balbuciadas com as mãos tiritando de frio e perante o olhar atento dos mais velhos. Importa, pois, interpretar o subtexto em seu específico contexto, porque só assim poderemos desconstruir o "mito da aceitação entusiástica" por parte dos calouros. Ou seja, "colocados perante um cenário de inevitabilidade [eles] sabem, isso sim, que se tentarem resistir serão ostracizados, 'desintegrados', por muitos colegas, quando não coagidos psicologicamente ou mesmo fisicamente” (Bebiano, 2014).

Note-se que o fenômeno é geral e ocorre em todas as universidades e institutos superiores do país. Para que se perceba seu alcance junto dos estudantes, basta recordar as frases que mais soaram num auditório da Universidade de Lisboa (em 2012) por ocasião de um debate em que foi apresentado o documentário cinematográfico de Bruno Cabral intitulado Praxis. ${ }^{25}$ Algumas das intervenções dos alunos destacaram ideias como "a praxe é uma humilhação que tem por objetivo criar um inimigo comum para os calouros, para que eles se interliguem" (rapaz, estudante mais velho); "o que eu senti quando fui caloura é que, quando me mandavam olhar para o chão eu trocava um olhar [por baixo] com o meu colega do lado, olhando para o chão, mas aí criava uma ligação com a pessoa que estava ao meu lado" (estudante trajada); "a praxe ensina-nos não a ler, não a escrever, mas que todos nós temos direito a ser humilhados"; "sou caloura e só digo uma coisa: eu amo a praxe!" (estudante caloura, a intervenção mais aplaudida).

Vejamos o caso de Alexandra Mendonça, de 33 anos, ex-estudante da Escola de Enfermagem São Vicente de Paulo, em Lisboa. Nas primeiras semanas após chegar do Algarve ela se divertira bastante com suas colegas que ingressaram no curso de enfermagem, apesar de os "padrinhos" lhe terem pintado o rosto, a terem chamado de "besta" e a obrigado a cantar a música da "vaca leiteira", em pleno Campo Grande, Lisboa. É impressionante o relato 
que apresentou dos momentos em que aguardava seu "julgamento", junto com outras/os colegas. De pé, junto à porta de uma sala fechada, ouvia gritos, vindos lá de dentro, que lhe pareciam de aflição. Não sabia o que se passava. Estava "um pouquinho nervosa", diz, mas nem pensar em contrariar o que lhe quisessem fazer. Finalmente, chega sua vez. Mandaram-na descalçar-se e pediram-lhe que entrasse, após o que se deparou com um tapete de percevejos com a ponta virada para cima, que atravessava toda a sala. No meio havia uma estreita faixa sem percevejos por onde teria de passar. Só que exigiram que o fizesse descalça e saltando numa perna só, depois de lhe vendarem os olhos. Alexandra não poderia imaginar que o tapete seria silenciosamente retirado tão logo ela fosse vendada. Enquanto isso, continuava a ouvir gritos agoniantes, que eram também simulados, embora ela não soubesse. Pensou que se os outros tinham conseguido passar pelos percevejos ela também conseguiria. "Eu acreditava mesmo que estava pulando num pé só e desviando-me dos percevejos... Foi horrível." Mais tarde, porém, acabou por entregar-se à causa.

Não é incomum a mudança de atitude quando se passa da condição de calouro para a de "doutor" (isto é, do primeiro para o segundo ano de faculdade). Na condição de calouros permanecem em geral expectantes ou até com medo, pelo menos de início. Muitos consideram aquelas brincadeiras patéticas, sem sentido, e toda a encenação um pouco ridícula. Depois mudam. Eles(as) mesmos(as) se surpreendem com isso, como declarou uma antiga estudante: "quando vesti o traje, senti-me outra". Mudar de "posto" implica passar a atuar de acordo com o que se espera da nova "patente". Numa palavra, a lógica de dominação não muda só porque ocorre uma troca entre os protagonistas ou se altera o status na hierarquia. Isso significa que o poder social é bem mais perverso e insinuante do que parece. Esses estudantes podem nunca ler Michel Foucault ou Pierre Bourdieu, mas com certeza aprendem rapidamente a desempenhar a função de veículos da capilaridade do poder simbólico e reproduzem-no em larga escala.

\section{CONCLUSÕES}

A partir dos diversos fragmentos que acabo de apresentar em torno das tradições acadêmicas e culturas estudantis é tempo de sintetizar algumas linhas de interpretação, que prefiro apresentar a título de hipóteses explicativas. Convém, entretanto, realçar que o tema "praxe" foi mais um pretexto do que um fim em si mesmo - pretexto para tentar conhecer mais de perto o universo de referências da atual juventude estudantil a partir do contexto, e da história, da UC. Invocar a tradição para promover atividades lúdicas e ritualistas que integram a praxe já faz parte da própria praxe. Como se sabe, porém, o discurso que apela para o passado é sempre reflexo do presente. Por esse motivo, a análise centrada na tradição acadêmica é, ao mesmo tempo, 
uma análise das narrativas centradas nessa tradição. É nesse sentido que, para uma tentativa de interpretação sociológica da praxe, é fundamental ter presente seu significado histórico, mas importa sobretudo centrar a atenção no(s) sentido(s) que ela vem adquirindo na atualidade.

Vale a pena por isso situar o assunto no quadro de tendências mais recentes que veem empurrando a juventude para crescentes individualismo e vulnerabilidade em face das perspetivas de futuro. Não é possível, porém, ignorar a herança mais antiga de um modelo de Estado providência e "sociedade de consumo" (ainda que construída tardiamente no caso português) que se expandiu a partir da década de 1980 . Um tal modelo de referência não se apagou, sobretudo entre famílias de classe média, aquelas que mais influência têm no mundo universitário. O imediatismo hedonista ou a alienação deliberada, de que falou Lipovetsky em A era do vazio, continuou a marcar as sociabilidades juvenis em Portugal, muito na linha de anteriores reflexões sobre "o crescimento inquietante da ansiedade, da depressão, de perturbações psicopatológicas comportamentais diversas. [...] A figura dominante do individualismo democrático foi, durante algum tempo, a euforia da libertação; agora, cada vez mais, é a dificuldade de viver, a insegurança, o medo ligado não só ao terrorismo, mas a qualquer coisa: alimentação, relações, idade, trabalho, aposentadoria" (2004: 2I). Sabemos bem que no contexto da recente crise a crescente "mercadorização" da economia, do trabalho e da sociedade acarretou maior indefinição e bloqueio das oportunidades para a juventude universitária, empurrando-a para uma relativa "indiferença" política e associativa (Estanque \& Bebiano, 2007). As perplexidades atuais, contudo, não apagaram muitos dos sinais que há várias décadas vêm sendo apontados à sociedade de consumo, com a massificação cultural, a instrumentalização dos títulos acadêmicos, a fragilização dos movimentos sociais emancipatórios e estudantis etc., sobretudo tendo em conta o contexto europeu (Marcuse, 1964; Castoriadis, I982; Debord, I983; Baudrillard, I991). Em Portugal os deficit de cidadania são antigos e profundos, e a crise da última década - apesar de também ter suscitado movimentos de contestação de grande impacto (a esse respeito, ver Estanque, 20I5) - não deixou de agudizar antigas patologias, medos e uma certa propensão para a "autoflagelação" (Gil, 2007; Santos, 2012). Olhando esse processo à luz das profundas transformações sociais que ocorreram no país, em especial desde a abertura democrática em 1974, é inquestionável seu enorme alcance no campo universitário e nos seus diversos espaços de sociabilidade (Estanque, 20I2; 20I6).

Como procurei mostrar a partir do caso da Universidade de Coimbra, as velhas componentes da boêmia, em que o lazer e o excesso se podiam conjugar com atividades culturais e contraculturas de resistência, foram substituídas por novos padrões de consumo formatados segundo os interesses do marketing e dos grandes patrocinadores das festas acadêmicas, em que o ex- 
cesso de consumo de álcool ${ }^{26}$ se tornou um sério problema. Essas tendências pulverizam as antigas atmosferas e subjetividades de sentido crítico, substituindo os velhos reportórios dos movimentos estudantis pela adesão às lógicas de mercado e seus objetivos lucrativos. As praxes são, pois, indissociáveis das tendências sociais mais gerais e, acima de tudo, da profunda mudança que a universidade vem sofrendo nas últimas décadas. Daí a inevitável alteração, senão mesmo "reinvenção", dessas tradições. Segmentos cada vez maiores de estudantes oriundos da classe trabalhadora passaram a ingressar nas universidades (públicas e privadas), imprimindo-lhe uma lógica de "massificação", ao mesmo tempo que o processo geral de modernização e urbanização da sociedade alterou significativamente o status social e os padrões de vida de suas famílias de origem. Os novos riscos urbanos e o desaparecimento dos antigos ambientes de rua, de aldeia ou de bairro, estimularam a atomização, o isolamento e a solidão entre as atuais gerações de adolescentes, pouco inclinadas ao envolvimento associativo e a denotar dificuldades nas sociabilidades secundárias.

A entrada no ensino superior oferece-se, assim, como um primeiro mergulho na vida coletiva, e isso ocorre numa fase da vida de intensa estruturação da personalidade social - em especial quando isso significa também deslocamento para uma cidade desconhecida - quando muitos jovens se sentem entregues a si próprios pela primeira vez. A valorização das amizades, das cumplicidades de grupo, da partilha entre colegas etc. é traço muito presente nas subjetividades da juventude estudantil. Daí resulta que a explicação para uma entrega tão incondicional a essas práticas terá de relacionar-se com a vontade indômita de integração ao grupo, a atitude de deslumbramento e o sentimento de solidariedade entre iguais, ao mesmo tempo que ocorre a vivência de uma ascensão de status, perante a vertigem de se aceder ao título de "doutor".

A juventude universitária portuguesa descobre-se, portanto, em sua inserção comunitária, o que quer dizer que a ideia vulgarizada de um individualismo generalizado entre os mais jovens não combina com a realidade. Os estudantes vivem em grande insegurança e quando ingressam na universidade sua vulnerabilidade individual fica mais exposta. É patente a dificuldade de eles construírem espaços de autonomia e iniciativas empreendedoras no plano pessoal. Por isso se reconhecem e projetam no grupo. O grupo de colegas torna-se sua principal ancoragem. O coletivo de amigos (em que se incluem "padrinhos" e colegas mais velhos) constitui o espelho que devolve a segurança e consolida a identidade social de cada um. Nesse sentido, os gestos de adesão à praxe e o "respeito" que os calouros são levados a demonstrar perante seus parceiros mais velhos significam, por um lado, que os momentos de "submissão" são vividos como transitórios, isto é, segundo a pers petiva de quem já se imagina "do lado de lá"; mas, por outro lado, as dinâmi- 
cas de grupo estimulam-nos a construir seu próprio sentido de emancipação, principalmente a partir do momento em que o "calouro" é promovido a "doutor". A volatilidade do status vivido obedece a uma lógica psicossocial de transferência projetiva, mas, nesse processo, a cultura de sujeição ao poder sai fortalecida e naturalizada.

A lógica de poder e a hierarquia vincada que a praxe reproduz fundamse no princípio puro da "força", embora permitindo a passagem rápida da submissão para dominação. Seja como for, o mergulho na praxe representa um teste de resistência perante a "autoridade". Uma autoridade que é a negação da democracia (ofende os direitos individuais) e da meritocracia (o mais veterano é o que teve maior insucesso escolar). É sob essa luz que se pode compreender que os jovens reivindiquem "o direito a ser humilhados", uma formulação que não deixa de ser paradoxal, mas que bem revela como esse jogo se impõe pela disponibilidade do elo mais fraco para a sujeição (ainda que passageira). O fato de hoje vivermos num quadro social de grande indefinição e perplexidade, a elevada apreensão e a incerteza com que o jovem olha seu próprio futuro contribuem para fortalecer sua entrega ao "aqui e agora" e para empurrar muitos desses jovens para uma pulsão evasiva que rejeita qualquer esforço reflexivo ou que procure desafiá-lo. Nesse aspecto, estamos perante um quadro que se situa nos antípodas das conjunturas de I969 (crise Acadêmica) ou de I974-I975 (a Revolução dos Cravos): no primeiro acaso, como vimos, foi um momento em que a "tradição" chegou a ser usada como pretexto ou "arma" para camuflar a irreverência; no segundo, a "tradição" não tinha lugar porque era considerada noção incompatível com a utopia socialista que mobilizou a juventude dessa época (em sua maioria) durante o chamado processo revolucionário em curso (mais popularmente conhecido por Prec).

Recebido em 08/02/2017 | Aprovado em 25/04/2017

Elísio Estanque é professor na Faculdade de Economia e pesquisador do Centro de Estudos Sociais da Universidade de Coimbra desde I985. Desde então tem lecionado, pesquisado e publicado sobre temas como classes e desigualdades sociais, sociologia da empresa e das relações laborais, sindicalismo, juventude e movimentos sociais. Doutorou-se em $1999 \mathrm{com}$ a tese Entre a fábrica e a comunidade, publicada em 2000. Seus livros mais recentes são: Praxe e tradição acadêmica (2016); Classe média e lutas sociais (20I5) e A classe média: ascensão e declínio (2012). 


\section{NOTAS}

* O presente texto apoia-se em projetos anteriores do autor ou em que esteve envolvido. Algumas passagens foram publicadas na obra Praxe e tradições académicas, Lisboa: Fundação Francisco Manuel dos Santos (FFMS), 2016. Agradeço, pois, à FFMS ter apoiado a pesquisa inicial e a publicação desse livro. O artigo beneficiou-se ainda do projeto coletivo A Praxe como Fenômeno Sociológico (Relatório Final), estudo patrocinado pela Direção Geral do Ensino Superior (DGES/MCES) - Governo Português (equipe integrada, além do autor, por João Teixeira Lopes, João Sebastião, João Mineiro e José Pedro Silva). Agradeço a ambas as instituições e ao governo português, liderado por António Costa, esse patrocínio e o incentivo ao estudo dessa temática.

A presente publicação resulta do apoio da Fundação para a Ciência e a Tecnologia portuguesa, ao abrigo do Projeto Estratégico (UID/SOC/50012/2013).

I Refira-se que o articulado do Código da Praxe, embora pareça ser muito minucioso, permite em grande parte dos casos leituras contraditórias. Além disso, abre muitas exceções que, na prática, subvertem em algumas alíneas o que foi estabelecido em outras.

2 Inquérito promovido conjuntamente pela Universia e pela comunidade de emprego Trabalhando.com, reunindo as mais importantes instituições de ensino superior da América Latina (I.345 universidades) que agregam I8,3 milhões de estudantes e professores, correspondendo a cerca de $79 \%$ do coletivo universitário ibero-americano. Dos 23 países incluídos na amostra a maioria é do continente sul-americano, dos EUA, de Portugal, de Andorra e da Espanha (ver Diário Económico, I4 dez. 20I5).

3 A criação do Estudo Geral Português, com a assinatura do documento "Scientiae thesaurus mirabilis", por dom Dinis, teve lugar em I mar. I290, confirmada pela bula "De statu regni Portugaliae", do papa Nicolau IV (9 ago. I290), com as faculdades de artes, direito canônico (cânones), direito civil (leis) e medicina, começando a funcionar em Lisboa. As mudanças de sede foram várias nos primeiros tempos - o então designado estudo geral passa para Coimbra em I308, regressa a Lisboa em I338 e de novo a Coim- 
bra em I354; volta a Lisboa em I377 e é definitivamente instalado em Coimbra em I537.

4 Há registros referindo que o grupo de delinquentes tentou raptar a filha do reitor, dr. Sanches de Baena.

5 António Nunes Ribeiro Sanches foi um importante cientista e intelectual do século XVIII (médico, filósofo, pedagogo, historiador), de origem judaica (tornou-se cristão novo). Estudou filosofia e direito em Coimbra, mas em I720 abandonou essa universidade com críticas ao tipo de ensino então ministrado e à vida boêmia dos estudantes. Vítima de perseguição, foi obrigado a exilar-se em I726, tendo viajado por toda a Europa e passado por diversas universidades, tais como Salamanca, Paris e São Petersburgo. Recebeu homenagens de Catarina II da Rússia e foi nomeado conselheiro de Estado naquele país. Foi membro da Academia de Ciências de São Petersburgo, Academia de Ciências de Paris e Sociedade Real de Londres. Entre as várias obras que publicou destaca-se Cartas sobre a educação da mocidade, de I760. Regressado da Rússia tornou-se conselheiro do marquês de Pombal, ajudando a promover a reforma da universidade. O trecho aqui citado por Cruzeiro consta de Método para aprender e estudar a medicina, obra de I763 decorrente de sua colaboração com o governo português), documentos atualmente incluídos na base de dados da Universidade da Beira Interior, disponíveis em <http://www.estudosjudaicos.ubi.pt/rsanches_obras/ metodo_aprender_estudar_med.pdf $>$.

6 O canelão era um castigo imposto ao calouro, em geral aplicado pelas trupes, que constava de pontapés nas canelas da vítima. Era comum, até ao século XIX, sobretudo no primeiro dia de aulas, quando o jovem recém-inscrito na UC atravessava a Porta Férrea, organizarem-se os mais velhos em duas alas, formando um túnel, pelo qual o calouro passava, enquanto os seus camaradas mais velhos o agrediam, o mais fortemente possível, com pontapés nas canelas, só escapando a lesões dolorosas, e às vezes graves, os que se fiavam em sua agilidade e rapidez.

7 A prisão funcionou num primeiro período em calabouços sob a Sala dos Capelos (o emblemático espaço da UC em que ainda hoje ocorrem as provas de doutorado) e mais tarde, após a reforma do marquês de Pombal, em instala- 
ções sob a Biblioteca Joanina. Na sequência da Revolução Liberal (1820), cujo principal foco foi a cidade do Porto (de grandes repercussões no país e também no Brasil, que se tornou independente logo após o regresso da corte a Portugal), foi extinto o Foro Acadêmico e com ele a jurisdição especial destinada a professores, estudantes e suas famílias, bem como o cárcere da UC.

8 O traje acadêmico evoluiu ao longo dos tempos, mas continua ainda hoje a ser marca bem presente na academia de Coimbra, sendo o negro seu traço mais distintivo. É particularmente visível nos períodos de ritualismo mais intenso - início do ano letivo, em setembro-outubro (recepção dos calouros e desfile da Latada), e mês de maio (desfile da Queima das Fitas) - embora ocorram rituais de praxe em Coimbra praticamente durante todo o ano letivo. A indumentária inclui capa e batina, e calça ou saia; consoante as situações deve ser, ou não, usada com as chamadas insígnias: fitas, de cores diferentes segundo a Faculdade, pasta negra em pele, grelo, bengala e cartola (chapéu alto), estes últimos usados por finalistas durante o desfile da Queima das Fitas.

9 Disponível em <http://notasemelodias.blogspot. $\mathrm{pt} / 2014 / 07 /$ notas-as-trupes-academicas-origens-e_ 2 . html>.

Io O Conselho de Veteranos é o órgão máximo na hierarquia da praxe acadêmica. Seus membros nomeiam seu chefe, que no caso de Coimbra é designado por Dux Veteranorum. Dele fazem parte (ou podem fazer) os estudantes cujo número de matrículas excede o número de anos letivos do respectivo curso.

II Existem no caso de Coimbra I7 categorias na hierarquia da praxe, desde a mais baixa, o bicho, que é o estudante do ensino secundário, até a mais alta, o Dux, o chefe máximo. "Pastrano" é o estudante de primeiro ano que se matriculou entre o período da Queima das Fitas e o início do ano letivo seguinte.

I2 A torre da universidade é constituída por um conjunto de sinos e relógios que, segundo a tradição, regulam o ritmo acadêmico (é conhecida como Cabra, embora esse seja o nome de apenas um dos sinos; os outros são conhecidos na gíria acadêmica como Cabrão e Balão). Há dois toques 
principais - o matutino, entre sete e meia e oito horas da manhã, e o vespertino, entre seis e seis e meia da tarde - que estabelecem a abertura e o encerramento das atividades letivas, respetivamente. Segundo o Código da Praxe, elas só são permitidas entre o primeiro toque matutino e o último vespertino; estão previstas, porém, várias situações de exceção. Ao longo do dia existem ainda os toques que marcam o início das aulas. O período das onze e meia da noite até a meia-noite é a chamada "hora do calouro", em que ele não pode ser praxado. Fora desse período, após o último toque da meia-noite, caso seja surpreendido na rua por uma trupe pode ser interpelado, julgado e punido.

I3 O Palito Métrico surgiu em I746 e teve sua última edição em I942. Trata-se de coletânea de publicações, com poemas, cartas e recomendações escritas em latim macarrônico, assinada em sua fase inicial por António Duarte Ferrão, pseudônimo atribuído a um presbítero secular, o padre João da Silva Rebello (I7IO-I790), doutor em teologia e cânones pela UC.

I4 O termo, de conotação pejorativa, é associado a negócio de baixa qualidade, conjunto de trastes velhos; vestuário barato etc. Vestir-se à futrica é vestir-se à paisana, com roupas reles ou de "pessoa sem importância". Em Coimbra a palavra diferencia estudantes e não estudantes.

I5 Repare-se a linguagem vernacular, bem ao estilo corrosivo e boêmio da tradição acadêmica de Coimbra, onde era comum o recurso à terminologia brejeira ou à fraseologia em latim macarrônico.

I6 Na época, essa designação era sinônimo de ex-emigrantes que regressaram do Brasil (em geral bem-sucedidos e, supostamente, abastados).

I7 Na origem dos primeiros movimentos "boêmios" estiveram personagens célebres como Charles Baudelaire, o percursor do simbolismo e do estilo flâneur ou dandy, cujas arte e poesia, bem como o estilo de vida errante e "marginal", visavam chocar e afrontar a moral dominante. Em muitos ambientes ao longo da Idade Média - mas sobretudo com a emergência da Era Moderna e o impacto das novas correntes filosóficas, em especial o Iluminismo -, poetas, músicos, artistas e intelectuais (muitos deles em ruptura com 
suas origens aristocráticas, nobres ou burguesas) mergulhavam na dimensão submersa e algumas vezes desbragada da cultura popular como ato de rebelião contra as convenções e a moral dominante. Como assinalei em texto anterior, o escritor e dramaturgo Henri Murger, em sua reflexão a partir da peça Bohèmes du Quartier Latin (I849), depois publicada em livro sob o título Scènes de la vie de bohème (Murger, I85I), foi o primeiro a promover e refletir sobre o conceito de boêmia. A existência de boêmios remonta, segundo esse autor, à Grécia clássica, época histórica em que surgiram as primeiras figuras boêmias, inicialmente associadas aos famintos e errantes, às vezes conotados como ladrões e vagabundos, que circulavam em redor de ambientes abastados e hospitaleiros, mendigando e tocando lira em dedicação a Helena e à queda de Troia. O fenômeno foi-se readaptando ao longo dos tempos e terá ganhado ligações a grupos nômades e sem rumo certo, de etnia cigana, e que, na Paris de meados do século XIX terão criado a ideia de ser oriundos da Boêmia, região da atual República Checa. Por analogia, grupos de artistas e intelectuais desse tempo (empobrecidos ou não) tais como G. Coubert, P. Verlaine, A. Rimbaud, E. Zola, H. Balzac etc., adotaram modos de vida com algumas características semelhantes, em particular, no sentido da recusa e da crítica aberta à moral dominante (Bakhtin, 20Io; Estanque, 20I0).

I8 O "Pantaleão" foi um "estudante-boémio", que cursou medicina e que promoveu a sua primeira "Reunião de Curso" com todos os colegas a apresentarem-se de chapéu de coco (ou chapéu alto), de bengala e fumando charuto, uma prática que viria a enraizar-se enquanto tradição nos meios académicos de Coimbra, que perdura até hoje. Companheiro de outra figura famosa da boémia de então, Castelão de Almeida, que foi Dux Veteranorum e fundador do jornal satírico O Ponney (criado em I929), o qual difundiu diversos textos corrosivos da conjuntura universitária e sociopolítica desse período de ditadura militar (I926-I933) e depois disso no início do Estado Novo, tendo chegado a ostentar o status de "jornal de maior circulação em Coimbra” (cf. O Ponney, Anno II $n^{\circ}$ 43. Coimbra: Tipografia Da Atlantida, I93I). 
I9 Artur Paredes, Carlos Paredes, António Portugal e António Brojo (na guitarra) e Augusto Hilário, Luiz Goes, José Afonso, Florêncio de Carvalho, Fernando Rolim, entre outros (no fado de Coimbra) são alguns dos artistas que se tornaram famosos, sobretudo a partir das décadas de 1950 e I960. Pouco depois começaram a desenvolver-se as novas sonoridades e a politização desse campo com a chamada música de intervenção (de que José Afonso foi o principal percursor).

20 Como condição para a admissão, recebeu instruções do reitor para trajar sempre de negro, com chapéu discreto e modo sóbrio de vestir, de forma a não se evidenciar entre os colegas do sexo masculino (Samara, 2007).

2 I Recorde-se a velha trilogia Deus, Pátria e Família, tão bem caricaturada na imagem de capa dos livros da antiga segunda classe.

22 Além desses dois nomes, outros músicos conotados com essa corrente merecem destaque, tais como: Luís Cília, Francisco Fanhais (padre Fanhais), José Mário Branco, Manuel Freire, José Jorge Letria, Sérgio Godinho, Fausto Bordalo Dias, Vitorino Salomé etc.

23 Recorde-se que algumas repúblicas permaneceram, até hoje, em modo de luto, uma vez que ele nunca foi encerrado pelo órgão que o "decretou", o Conselho de Repúblicas, em que as decisões, segundo seus estatutos, são tomadas por unanimidade.

24 Um desses momentos simbólicos ocorreu em 2 de junho de Ig69 na final da Taça de Portugal em futebol, jogada no Estádio Nacional, em Lisboa, entre o Benfica e a Acadêmica de Coimbra, no rescaldo da crise acadêmica, quando os jogadores de futebol entraram em campo com as capas negras aos ombros, simbolizando sua solidariedade à luta estudantil.

25 Filme muito elucidativo do nível de perversão e de violência que os rituais da praxe têm conduzido em Portugal. Vale a pena consultar e visualizar: <http://uniarea.com/ praxis-documentario-do-que-nao-deve-ser-a-praxe-oureproducao-fiel/>.

26 Muito sintomático do apelo ao consumo e ao excesso subjacente à cultura "praxista" é, por exemplo, o fato de se 
prever no Código da Praxe (art. I62 do Código atualizado em janeiro de 20I6) que uma das situações em que o calouro fica "autoprotegido" (leia-se, impedido de ser praxado) é quando está sob a "proteção do Deus Baco", isto é, "fortemente embriagado".

\section{REFERÊNCIAS BIBLIOGRÁFICAS}

Anônimo. (I96I). Carta a uma jovem portuguesa. Jornal Via Latina - órgão da Associação Acadêmica de Coimbra, I30. Assembleia da República. (2008). As praxes académicas em Portugal. Relatório da Comissão Parlamentar de Educação e Ciência. Lisboa.

Bakhtin, Mikhail. (20Io). Cultura popular na Idade Média: o contexto de François Rabelais. São Paulo: Hucitec.

Bastos, Henrique Teixeira. (I920). A vida do estudante de Coimbra, antiga e moderna: duas conferências na Associação Cristã de Estudantes, nos dias 29 e 30 de abril de I920. Coimbra: Imprensa da Universidade.

Baudrillard, Jean. (I99I). Simulacros e simulação. Lisboa: Relógio D’Água.

Bebiano, Rui. (2014). Cinco mitos em torno das praxes. Esquerda.Net. Disponível em <http://www.esquerda.net/ dossier/cinco-mitos-em-torno-das-praxes/31287.> Acesso em I2 set. 2015 .

Cruzeiro, Luc \& Chiapello, Ève. (200I). Le nouvel esprit du capitalisme. Paris: Gallimard.

Braga, Paulo Drumond. (2004). Aspectos do quotidiano universitário no período filipino. In: Estudos em homenagem a Luís António de Oliveira Ramos. Porto: Faculdade de Letras da Universidade do Porto, p. 313-320.

Braga, Teófilo. (1892-I902). História da Universidade de Coimbra nas suas relações com a Instrução Pública Portuguesa. 4 v. Lisboa: Academia Real das Ciências.

Cardina, Miguel. (2008a). A tradição da contestação: resistência estudantil em Coimbra no marcelismo. Coimbra: Angelus Novus.

Cardina, Miguel. (2008b). Memórias incómodas e rasura do tempo: movimentos estudantis e praxe académica no 
declínio do Estado Novo. Revista Crítica de Ciências Sociais, 8I, p. III-I3I.

Castoriadis, Cornelius. (I982). A instituição imaginária da sociedade. Rio de Janeiro: Paz e Terra.

Coelho, Trindade. (I902). In illo tempore: estudantes, lentes e futricas. Paris/Lisboa: Livraria Aillaud \& Cia.

Cruzeiro, Celso. (1989). Coimbra, I969. A crise académica, o debate das ideias e a prática, ontem e hoje. Porto: Afrontamento. Cruzeiro, Manuela \& Bebiano, Rui. (2006). Anos inquietos. Vozes do movimento estudantil em Coimbra (196I-I974). Porto: Afrontamento.

Cruzeiro, Maria Eduarda. (1979). Costumes estudantis de Coimbra no século XIX: tradição e conservação institucional. Análise Social, XV/6o, p. 795-838.

Debord, Guy. (1983). Society of the spectacle. Detroit: Black \& Red. Dias, Diana \& Sá, Maria José. (2013). Rituais de transição no ensino superior português: a praxe enquanto processo de recomposição identitária. Revista Galeco-Portuguesa de Psicoloxía de Educación, 2I/I, ano I8, p. 2I-34.

Elias, Norbert. (1989). O processo civilizacional. Lisboa: Dom Quixote (v. I e II).

Estanque, Elísio. (2016). Praxe e tradições académicas. Lisboa: Fundação Francisco Manuel dos Santos.

Estanque, Elísio. (20I5). Classe média e lutas sociais: ensaio sobre sociedade e trabalho em Portugal e no Brasil. Campinas: Ed. Unicamp.

Estanque, Elísio. (2014). A praxe e o novo tribalismo. Público, 22 de out., Lisboa. Disponível em <https://www.publico.pt/20I4/Io/22/sociedade/noticia/ a-praxe-e-o-novo tribalismo-1673627>. Acesso em 30 jul. 2017.

Estanque, Elísio. (2012). A classe média: ascensão e declínio. Lisboa: Fundação Francisco Manuel dos Santos.

Estanque, Elísio. (2010). Juventude, boemia e movimentos sociais: culturas e lutas estudantis na universidade de Coimbra. Política \& Sociedade, 9/ı6, p. 257-29o.

Estanque, Elísio \& Bebiano, Rui. (2007). Do activismo à indiferença. Movimentos estudantis em Coimbra. Lisboa: Instituto de Ciências Sociais. 
Foucault, Michel. (1977). Vigiar e punir. Petrópolis: Vozes. Frias, Aníbal. (2009). A 'arte' da contestação na Academia de Coimbra nos anos 60: Desenhos, caricaturas, praxe. Actas do V Congresso Português de Sociologia, Braga.

Frias, Aníbal. (2003). Praxe académica e culturas universitárias em Coimbra. Lógicas das tradições e dinâmicas identitárias. Revista Crítica de Ciências Sociais, 66, p. 8I-II6. Gama, Arnaldo. (1964) [1866]. A caldeira de Pero Botelho. Porto: Livraria Civilização.

Gennep, Arnold Van. (198I) [1909]. Les rites de passage étude systematique. Paris: Uitg. E. Nourry.

Gil, Fernando. (2007). Portugal hoje: o medo de existir. Lisboa: Relógio D’Água.

Lamy, Alberto Sousa. (I990). A Academia de Coimbra, I537I990, história, praxe, boémia e estudo, partidas e piadas, organismos académicos. 2 ed. Lisboa: Rei dos Livros.

Lipovetsky, Gilles. (2005). A era do vazio. Lisboa: Edições 70. Lipovetsky, Gilles. (2004). Metamorfoses da cultura liberal. Porto Alegre: Editora Meridional.

Marcuse, Herbert. (I982) [I964]. O homem unidimensional. Sobre a ideologia da sociedade industrial avançada. Rio de Janeiro: Zahar Editores.

Martins, Alberto. (1982). Coimbra 69: um pulsar de liberdade. Jornal Expresso, Lisboa.

Murger, Henri. (185I). Scènes de la vie de Bohème. London: Vizetelly \& C.

Namorado, Rui. (1989). Para uma universidade nova: crónica da crise de 1969 em Coimbra. Revista Crítica de Ciências Sociais, 27-28, p. 63-I24.

Notas \& Melodias. Disponível em <http://notasemelodias. blogspot.pt/>. Acesso em 30 jul. 2017.

Nunes, António Manuel M. (2004). As praxes académicas. Sentido actual e perspectivas. Cadernos do Noroeste, Instituto de Ciências Sociais da Universidade do Minho, 22/I-2, p. I33-I 49.

Nunes, António Manuel M. (1989). Subsídios para o estudo genético-evolutivo do hábito talar. Via-Latina, Ad Libitum, V Série. 
Prata, Manuel Alberto Carvalho. (2002). A Academia de Coimbra (I880-1926). Contributo para a sua história. Coimbra: Imprensa da Universidade.

Samara, Maria Alice. (2007) Operárias e burguesas. As mulheres no tempo da República. Lisboa: Esfera dos Livros.

Santos, Boaventura S. (2012). Portugal. Ensaio contra a autoflagelação. Coimbra: Almedina.

Torgal, Luís Reis \& Dias, Pedro. (2015). A Universidade de Coimbra. 2 ed. Coimbra: Imprensa da Universidade de Coimbra. 


\section{A PRÁXIS DO TROTE: BREVE ETNOGRAFIA HISTÓRICA DOS RITUAIS ESTUDANTIS DE COIMBRA}

\begin{abstract}
Resumo
$\mathrm{O}$ artigo procede inicialmente a uma breve contextualização histórica da Universidade de Coimbra, retratando alguns dos contornos das tradições acadêmicas, dentre os quais se destacam: a violência associada aos rituais iniciáticos da chamada praxe e a conflitualidade que, ao longo dos séculos, marcou as relações entre a elite estudantil e a comunidade local. Em seguida, explora possíveis conexões entre as praxes e os múltiplos movimentos culturais e sociopolíticos, incluindo a questão da subalternização da mulher e a resistência estudantil ao regime ditatorial de Salazar-Caetano. Por fim, analisa as tendências mais recentes que o fenômeno vem adquirindo em Portugal, muitas vezes resvalando para abuso, humilhação e violência. A cultura de submissão perante o poder que a maioria das praxes promove parece exprimir tendência larvar na sociedade, em que o individualismo consumista se combina de forma perversa com mecanismos de evasão e de entrega incondicional a lógicas disciplinares de teor despótico.
\end{abstract}

\section{"HAZING'S PRAXIS": BRIEF HISTORICAL ETHNOGRAPHY OF THE STUDENTS' TRADITIONS IN COIMBRA}

\footnotetext{
Abstract

The article firstly presents a brief historical context of the University of Coimbra, depicting some of the outlines of its academic traditions. Among these are: practices of bullying and violence associated with freshmen initiation rituals, the so-called praxe, and the conflicts that have characterized the relationship between the student elite and the local community over the centuries. Then it explores possible connections between these rituals and multiple cultural and sociopolitical movements, including the question of the subalternization of women and the student movements against the dictatorial regime of Salazar-Caetano. Finally, it analyzes the most recent trends that the phenomenon has been acquiring in Portugal, often resulting in abuse, humiliation and violence in the wake of controversial and tragic cases. The culture of submission to power that most rituals promote seems to express a recent trend in society and the youth, where consumerist individualism is combined in a perverse way with mechanisms of evasion and unconditional surrender to disciplinary logic of a despotic nature.
}

Palavras-chave

Praxe/trote; tradição acadêmica; movimento estudantil; Universidade de Coimbra; Portugal.

\section{Keywords}

Praxe; academic tradition; students' movement; University of Coimbra; Portugal. 